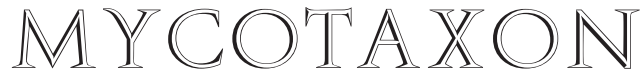

Volume 122, pp. 399-411

http://dx.doi.org/10.5248/122.399

\title{
Phylogenetic relationships and the newly discovered sexual state of Talaromyces flavovirens, comb. nov.
}

\author{
Cobus M. Visagie ${ }^{1,2^{*}}$, Xavier Llimona ${ }^{3}$, Jordi Vila ${ }^{3}$, \\ Gerry Louis-Seize ${ }^{1}$ \& Keith A. Seifert ${ }^{1}$ \\ ${ }^{1}$ Biodiversity (Mycology), Eastern Cereal and Oilseed Research Centre \\ Ottawa, Ontario, K1A 0C6, Canada \\ ${ }^{2}$ Department of Microbiology, University of Stellenbosch \\ Stellenbosch, 7600, South Africa \\ ${ }^{3}$ Departament de Biologia Vegetal (Botànica), Universitat de Barcelona \\ Diagonal 643, E-08028 Barcelona, Spain \\ *Correspondence to: cobusvisagie9@gmail.com
}

\begin{abstract}
Aвstract - Typical Talaromyces ascomata were observed on dry Quercus suber leaf litter amongst the characteristic synnemata of Penicillium aureocephalum, and they appear to represent the sexual state of the latter species. The species is a synonym of the older Lasioderma flavovirens, and we propose the new combination Talaromyces flavovirens. Lectotype and epitype specimens are designated for this name. The defining characters of the asexual state include yellow, short-stalked, mycetozoan-like synnemata with an unusual, almost closed terminal head of penicillate conidiophores intermixed with sinuous hyphae, and dark green conidia. Ascomata could not be induced in culture, but PCR amplifications of mating-type genes indicate the species is heterothallic. In nature, ascocarp initials appear to be antheridia coiled around clavate ascogonia, similar to those of $T$. flavus, and the thick-walled, spiny ascospores are also similar to those of T. flavus. ITS barcodes and $\beta$-tubulin sequences place $T$. flavovirens in a clade with T. apiculatus, T. flavus, T. funiculosus, T. galapagensis, T. pinophilus, T. macrosporus, and seven other species.
\end{abstract}

KEYwORDs - anamorph-teleomorph connections, DNA barcoding, hyphomycetes, Trichocomaceae.

\section{Introduction}

Penicillium aureocephalum was described as a new species of synnematous hyphomycete from Catalonia, Spain (Muntañola-Cvetković et al. 2001). It typically occurs on Quercus suber and Cistus salviifolius leaf litter, producing synnemata that resemble stalked mycetozoan sporangia. Although difficult to observe without micro-dissection, the synnemata have symmetrical 
conidiophores typical of Talaromyces (formerly referred to as Penicillium subg. Biverticillium), with long, thin acerose phialides and a phialide:metulae length ratio of about 1:1 (Pitt 1979). In culture on malt extract agar, P. aureocephalum typically produces hirsute yellow structures that resemble ascomata of Talaromyces, but they do not mature, even after months of incubation (Muntañola-Cvetković et al. 2001).

A subsequent study of the distribution of $P$. aureocephalum in Spain yielded abundant collections on Quercus leaves (Llimona et al. 2006). On some specimens, ascocarps resembling those of Talaromyces, with prolate spiny ascospores, were observed among the synnemata. Subsequent isolations from these asci resulted in the production of synnemata cultivation of $P$. aureocephalum in the pure cultures. This, the habitat specificity and the sometimes intertwined biverticillate conidiophores and asci led to our conclusion that the ascomata represent the sexual stage of $P$. aureocephalum.

Montagne (1845) described the monotypic genus Lasioderma, with its type species L. flavovirens collected on Quercus suber leaf litter from Algeria. The original description reads, "Peridium e turbinato obpyriforme e floccis septatis ramosis laxe intricatis contextum, subpersistens. Sporæ minutæ, numerosisimæ, contiguæ, olivaceæ in centro evanescente peridii conglutinate." The species diagnosis adds only a few details, "stipite rufo statim in capitulum globosum luteum dilatato," then refers to an 'ic. ined.' The color illustration was published the following year in Flore d'Algérie Durieu (1846). The corresponding Flore d'Algérie text (Durieu 1848) presented an essentially identical diagnosis, additional details of a location near la Calle, Algeria (i.e. on the Mediterranean coast), details of an earlier Spanish collection made in 1824 by Durieu (selected as lectotype below), an earlier unpublished manuscript name ("Cephalotrichum flavovirens Durieu," not to be confused with the validly published name Cephalotrichum flavovirens (Alb. \& Schw.) Nees), and clarification of how Lasioderma differed from Trichoderma.

The original and expanded descriptions (Montagne 1845, Durieu 1848), color plate (Durieu 1846; reproduced in MycoBank MB120473), specific habitat, and geographical location are all suggestive of $P$. aureocephalum. Its specific habitat and the striking morphological similarities between the Durieu (1846) sketch and $P$. aureocephalum synnemata led us to believe that they might be the same fungus. The suspicion was confirmed by our examination of authentic material in PC, from which we selected the lectotype below.

Seifert et al. (2012) reviewed the historical literature on Lasioderma, tracing its fate through Saccardo's (1886) and Lindau's (1900) hyphomycete compilations until it was deflected into the Basidiomycetes by Höhnel (1910) and then largely forgotten. We rediscovered the name because of its inclusion in the host index by Oudemans (1920). Because Lasioderma is an older name than Talaromyces, 
and Lasioderma is also the current name of a genus of beetles, Seifert et al. (2012) proposed the conservation of Talaromyces over Lasioderma. However, L. flavovirens remains a valid species name, predating $P$. aureocephalum by more than 150 years. The recent move to single name nomenclature has placed Penicillium subg. Biverticillium in synonymy with Talaromyces (Houbraken \& Samson 2011). Therefore, in this paper we introduce the new combination Talaromyces flavovirens and report our efforts to document the connection of the newly recognized sexual stage and its better-known synnematous stage. To supplement the recent phylogenetic analysis of Talaromyces by Samson et al. (2011), we also present the results of ITS and $\beta$-tubulin sequencing of multiple strains of this fungus, demonstrating its coherence as a phylogenetic species and confirming its relationships with other asexual Talaromyces species.

\section{Materials \& methods}

\section{Cultures}

Quercus suber leaf litter with visible colonies of T. flavovirens was collected in Catalonia, Spain by XL and his collaborators. Cultures were isolated from conidial masses from these specimens by KAS. Dried specimens are deposited in the Canadian National Mycological Herbarium (DAOM) and the cultures in the Canadian Collection of Fungal Cultures (CCFC) under accession numbers DAOM 236381-DAOM 236383.

\section{Morphology}

The fungus was characterized from its natural habitat (Q. suber leaves) and by using standardized cultivation techniques on Czapek Yeast Autolysate agar (CYA), Difco Malt Extract agar (MEA; Pitt 1979, Okuda et al. 2000) and Yeast Extract Sucrose agar (YES, Frisvad \& Samson 2004). Spore suspensions were prepared in semi-solid $0.2 \%$ agar with $0.05 \%$ Tween 80 and inoculated onto $9 \mathrm{~cm}$ Petri dishes in three-point pattern using a micropipette. All plates were incubated in the dark for 7 days at $25^{\circ} \mathrm{C}$, with additional CYA plates incubated at 5 and $37^{\circ} \mathrm{C}$. Color names and alphanumeric codes used in the species description refer to Kornerup \& Wanscher (1966). Microscopic characters were photographed using an Olympus BX50 compound microscope, or an Olympus SZX12 dissecting microscope, with an Evolution MP digital microscope camera operated by ImagePro 6.0. Composite habit photographs were produced using CombineZM (Hadley 2006). Conidiophore morphology was examined from both synnemata on the Quercus leaves and cultures grown on MEA.

\section{Phylogeny}

DNA was extracted using the UltraClean ${ }^{\mathrm{TM}}$ Microbial DNA Isolation Kit (MoBio Laboratories Inc.). ITS barcodes (Schoch et al. 2012) and partial $\beta$-tubulin genes were amplified using Illustra pureTaq Ready-To-Go ${ }^{\mathrm{TM}}$ PCR Beads (GE Healthcare) with primers ITS1 and ITS4 (White et al. 1990), and Bt2a and Bt2b (Glass \& Donaldson 1995). The PCR profile had an initial denaturing step of $95^{\circ} \mathrm{C}$ for $3 \mathrm{~min}$ followed by 35 cycles of $95^{\circ} \mathrm{C}$ for $1 \mathrm{~min}$, annealing at $56^{\circ} \mathrm{C}$ for $45 \mathrm{sec}$ and elongation at $72^{\circ} \mathrm{C}$ for $1 \mathrm{~min}$, followed by a final elongation step at $72^{\circ} \mathrm{C}$ for $7 \mathrm{~min}$. PCR products were sequenced using the same primers, with the Big Dye Terminator Cycle Premix Kit and products 
run on an ABI PRISM ${ }^{\mathrm{TM}} 310$ DNA automated sequencer (Applied Biosystems). Contigs were assembled and edited in CodonCode Aligner v3.7.1.1 (Codon Code Corporation). GenBank accession numbers are included on FIG. 1.

The ITS sequences of the $T$. flavovirens strains were compared to a database of Talaromyces spp. compiled from Samson et al. (2011). Reference strains of closely related and other synnema-producing species were included in a more focussed analysis of the $\beta$-tubulin gene region. Both data sets were aligned using MAFFT v6.850b (Katoh et al. 2009) using the L-INS-i option. Sequence analysis was done in PAUP*v4.0b10 (Swofford 2002). The BioNJ method was chosen for calculating a single tree for each data set (Gascuel 1997), with Trichocoma paradoxa chosen as suitable outgroup for the ITS analysis and a clade of synnema-producing species for the $\beta$-tubulin analysis. Bootstrap support was calculated using a 1000 replicates.

\section{Teleomorph-anamorph connection and mating experiments}

Various approaches were used to prove the connection between the sexual and asexual structures on the newly collected specimens. Cultures were isolated from conidial masses from Quercus suber leaves, and ascospore isolates were also attempted.

Anticipating that ascospores might be more heat resistant than conidia, we prepared spore suspensions prepared from both ascomata and synnemata in a semi-solid agar solution (Pitt 1979). Individual suspensions were exposed to temperatures at $5^{\circ}$ increments from $50-70^{\circ} \mathrm{C}$, for either 15 or $30 \mathrm{~min}$. Unheated suspensions were used as a positive control. After heating, spore suspensions were plated out onto MEA and incubated for 7 days at $25^{\circ} \mathrm{C}$, after which plates were inspected for growth.

All cultures were grown on CYA, MEA and Oatmeal agar (OA), and on 2\% water agar with twigs or leaves of Q. macrocarpa in $9 \mathrm{~cm}$ Polystyrene Petri dishes sealed with Parafilm. Further, the strains DAOM 236381-236383 and IBT 27044 were crossed in all possible combinations on $\mathrm{OA}$, and on $2 \%$ water agar with Q. macrocarpa leaves. After several months of incubation at RT under ambient light, the Parafilm was removed to allow the agar to dry out (López-Villavicencio et al. 2010), in an attempt to mimic the species' arid natural habitat.

Mating-type genes were amplified from all strains using the primers MAT1-1b and MAT1-2b with a touchdown PCR (López-Villavicencio et al. 2010). The PCR profile had an initial denaturing step at $95^{\circ} \mathrm{C}$ for $5 \mathrm{~min}$, followed by 30 cycles of denaturing at $95^{\circ} \mathrm{C}$ for $30 \mathrm{sec}$, annealing starting at $60^{\circ} \mathrm{C}$ (decreased $-0.5^{\circ} \mathrm{C}$ for every cycle until $50^{\circ} \mathrm{C}$ ) for 30 sec, elongation at $72^{\circ} \mathrm{C}$ for $1 \mathrm{~min}$, followed by a final elongation step at $72^{\circ} \mathrm{C}$ for $7 \mathrm{~min}$ (López-Villavicencio et al. 2010). To confirm the presence or absence of the MAT1 and MAT2 genes, products were run on a $1 \%$ agarose gel. In addition, representative strains containing the putative MAT genes were sequenced to confirm results, using the same sequencing protocol described above. MAT1 and MAT2 sequences were deposited in GenBank with accession numbers JX091392-JX091394.

FIgURE 1. Phylogenetic trees showing the relationships of Talaromyces flavovirens within Talaromyces. Trichocoma paradoxa was chosen as outgroup in the ITS phylogeny (left). For the $\beta$-tubulin phylogeny (right), only close relatives were included in the data set. The phylogeny was rooted to other synnema-producing Talaromyces species. Numbers above thick branches represent bootstrap values above $80 \%$. $\left({ }^{\mathrm{T}}=\right.$ ex-type strain; ${ }^{\star}=$ synnemata producer $)$. 
Teleomorph of Talaromyces flavovirens comb. nov. ... 403

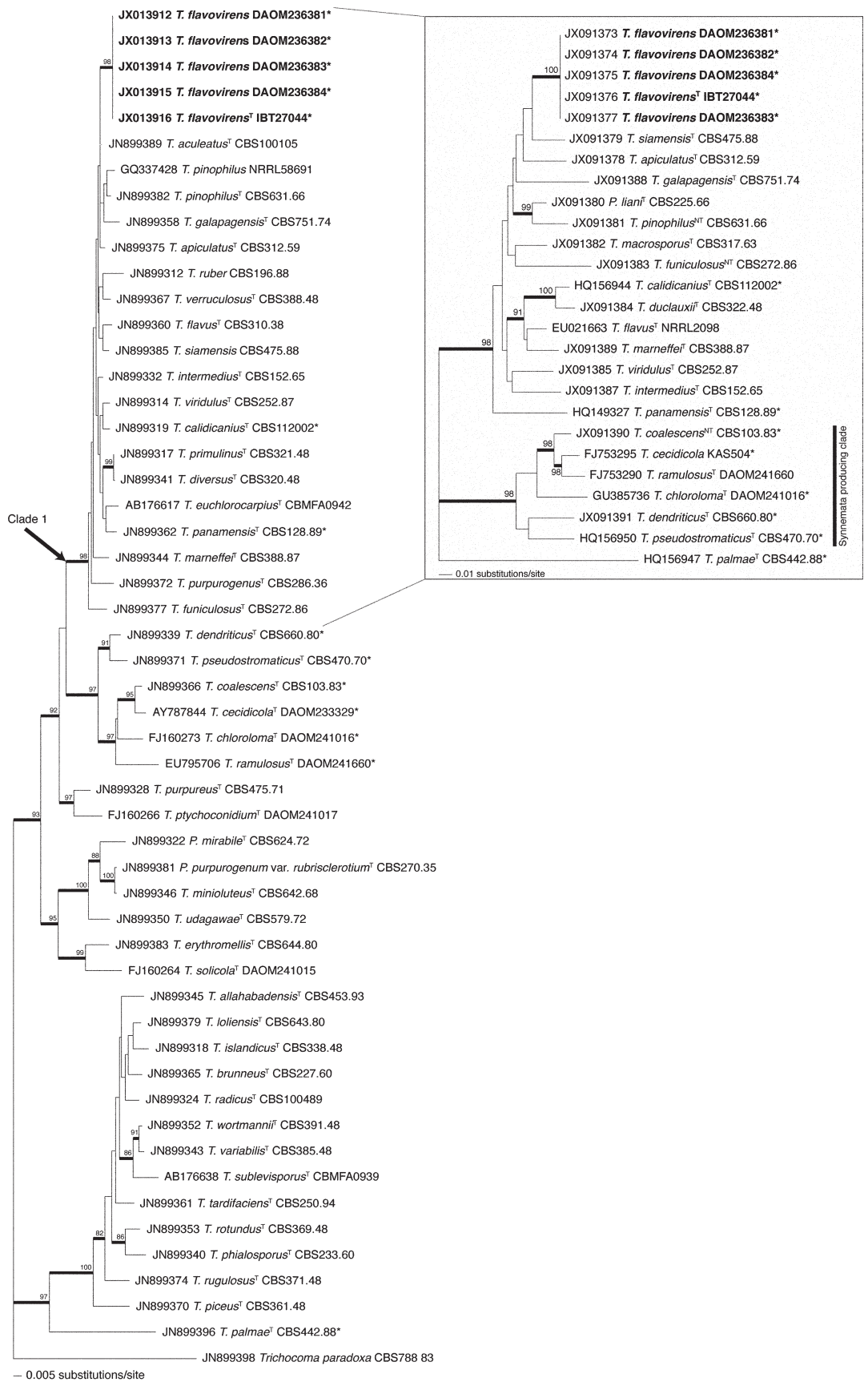




\section{Results}

Isolations from both synnemata and ascomata yielded conidiomata of the asexual state. Because of their small sizes, we could not confidently separate ascospores from conidia under the dissecting microscope, but all attempted ascospore isolations yielded the same synnemata that occurred in conidiumderived isolates. The resulting colonies are described below in the Taxonomy section.

Amplification of ITS barcodes resulted in amplicons about 600 bp long. The aligned data set of Talaromyces species was 471 bp long. Talaromyces flavovirens was resolved as a subclade of clade1, as described by Samson et al. (2011). Bootstrap supports were low for branches within this clade. Because $\beta$-tubulin is very difficult to align across the whole genus, we restricted our analysis of this gene to close relatives identified by the ITS analysis, and we included other synnema-producing species as out groups. $\beta$-tubulin amplicons were about $500 \mathrm{bp}$ long, but the confidently aligned portion of the data set was only 391 bp long. Branch lengths were longer than for the ITS phylogeny, but bootstrap support was still low. ITS and $\beta$-tubulin analyses resulted in different tree topologies. Although the sister group relationships differed between the two phylogenies, both analyses portrayed T. flavovirens as a phylogenetically distinct and coherent species.

No ascomata were observed in uncrossed or crossed cultures of T. flavovirens. All strains produced the characteristic yellow, hirsute structures described by Muntañola-Cvetković et al. (2001), but no ascocarp initials or ascospores were observed. Amplification and sequencing of the MAT genes showed that $T$. flavovirens is heterothallic, with DAOM 236382 having the MAT1 gene and other strains possessing the MAT2 gene.

The temperature gradient experiment did not reveal any difference in heat tolerance between ascospores and conidia, and thus was unhelpful in confirming the relationship of the two morphs. In both kinds of spore suspensions, positive controls grew within 7 days. Both ascospores and conidia were killed at $65^{\circ} \mathrm{C}$ with a 15 min exposure.

\section{Taxonomy}

Talaromyces flavovirens (Durieu \& Mont.) Visagie, Llimona \& Seifert, comb. nov.

MycoBAnK MB800438

Plates 1, 2

三Lasioderma flavovirens Durieu \& Mont., Annls Sci. Nat., Bot., 3e sér., 4: 364. 1845.

TyPE: Spain, Madrid, Parque del Retiro, on dead leaves of Quercus ilex, Nov. 1824, M.C. Durieu de Maisonneuve (lectotype designated here, PC 0088796); Spain, Catalonia, Gerona, Selva de Mar, 5.XII.1999, X. Llimona (epitype designated here, BCC $473=$ BCN 473 ; ex-epitype culture IBT 27044 = CBS 102801).

= Penicillium aureocephalum Munt.-Cvetk., Hoyo \& Gómez-Bolea, Fungal Diversity 7: 73 . 2001. 

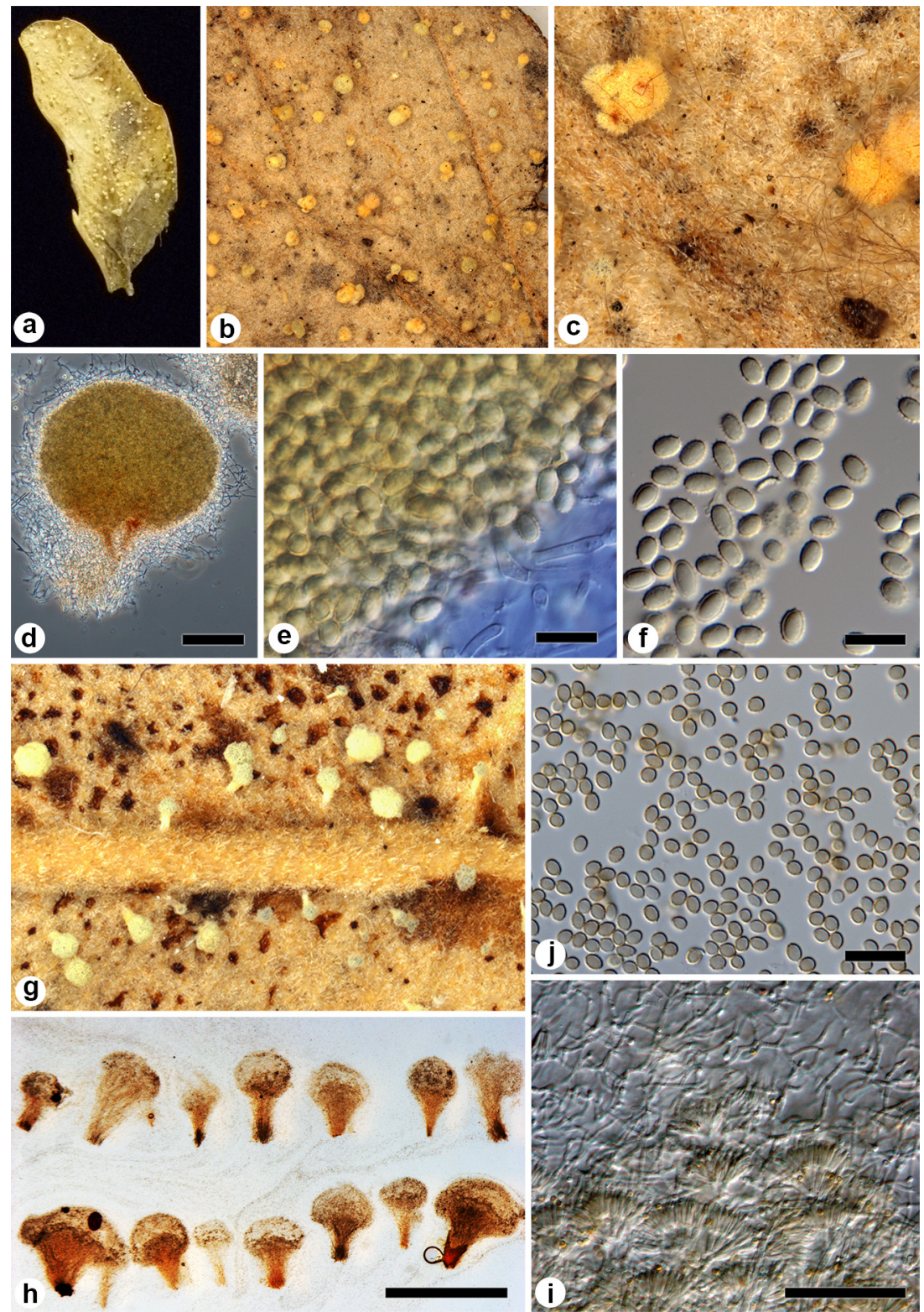

h

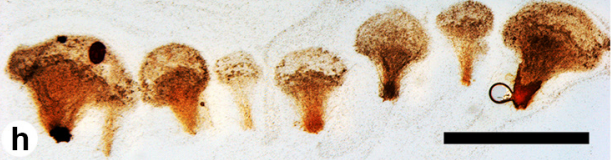

Plate 1. Talaromyces flavovirens as it occurs in nature. a,b. Quercus suber leaves containing the characteristic yellow synnemata and orange gymnothecia of T. flavovirens. c,d. Gymnothecia on Quercus suber. e,f. Heavy walled spinose ascospores. g,h. Synnemata produced on Quercus suber. i. Conidiophores in synnema with typical capitulum. j. Ellipsoidal heavy walled conidia produced. Scale bars: $\mathrm{d}=100 \mu \mathrm{m} ; \mathrm{e}, \mathrm{f}, \mathrm{j}=10 \mu \mathrm{m} ; \mathrm{h}=1000 \mu \mathrm{m} ; \mathrm{i}=50 \mu \mathrm{m}$. 
Type: SPAIN, Catalonia, Gerona, Selva de Mar, 5.XII.1999, X. Llimona (holotype of Penicillium aureocephalum, BCC $473=$ BCN 473; ex-type culture IBT $27044=$ CBS 102801)

In NATURE - Ascomata deep golden yellow, often with a reddish pigment, globose to subglobose, 150-380 $\mu \mathrm{m}$ diam, soft, covered by a loose network of hyphae, with a synnema-like stalk connecting ascomata to leaves, 50-100 $\times$ 15-50 $\mu \mathrm{m}$. Presumed ascocarp initials badly deteriorated, but similar in shape to those of Talaromyces flavus and T. macrosporus as illustrated by Stolk \& Samson (1972), with antheridia coiled around clavate ascogonia. Ascospores abundantly produced, prolate, spiny, with a thick wall that appears doublelayered, yellow, $(4-) 4.5-6(-7) \times 3-4$, $($ mean \pm stdev $=5.1 \pm 0.43 \times 3.5 \pm 0.2)$ $\mu \mathrm{m}$, mean width/length ratio $=0.69 \pm 0.06, \mathrm{n}=95$. Synnemata similar in appearance to stipitate myxostelid sporangia, with a yellow stalk 400-750 $\mu \mathrm{m}$ high, 100-250 $\mu \mathrm{m}$ wide at the base, and a terminal head 250-300 $\mu \mathrm{m}$ diam comprised of conidiophores and conidia, covered with a bright yellow layer of interwoven sterile hyphae, adding an additional 90-160 $\mu \mathrm{m}$. ConidiopHores mostly biverticillate, with very few subterminal branches occurring, dimensions and other features similar to those described below for cultures, but with metulae consistently diverging at broader angles, perhaps a consequence of the presumably older age of the synnemata on the observed specimens.

In CUlture - On CYA at $25^{\circ} \mathrm{C}$ after 7 DAYs - Colonies 11-13 mm, low, planar; texture velutinous; mycelia white; conidiogenesis moderate, conidia dark green (29F6-29F7) in mass; exudate absent, soluble pigment absent; margins narrow (1-2 mm), subsurface, entire; reverse Greyish Green (30D5) under inoculum, Greyish Green (30B3) elsewhere, fading into a Greenish White (30A2) margin. After prolonged incubation, colonies develop a brick red reverse. On MEA at $25^{\circ} \mathrm{C}$ after 7 DAYs - Colonies 28-31 mm, low, zonate; texture velutinous, appearing almost granular; sometimes dominated by sterile Sulphur Yellow (1A5) mycelia that mask conidial areas; conidiogenesis moderately dense to dense, conidia Dark Green (29F8) in mass; exudate absent, soluble pigment absent; margins wide, 4-6 $\mathrm{mm}$, subsurface, entire; reverse Light Yellow to Reddish Yellow (4A5-4A6) at colony centres, fading to Pale Yellow (2A3-2A4) near margins when aerial mycelia are present, or in colonies lacking aerial mycelium with zonate rings of Greyish Green (30E5) and Greyish Yellow (1B4). After prolonged incubation, colonies produce synnemata similar in appearance to those seen in nature, differing by having shorter stipes; often so densely packed that individual synnemata cannot be distinguished, and conidial heads then seeming confluent. After prolonged incubation, yellow hirsute structures produced, which resemble sterile ascomata. On YES at $25^{\circ} \mathrm{C}$ after 7 DAYs - Colonies 18-21 mm, low, planar; mycelia white; texture velutinous, with poorly developed funicles; conidiogenesis dense, conidia in 

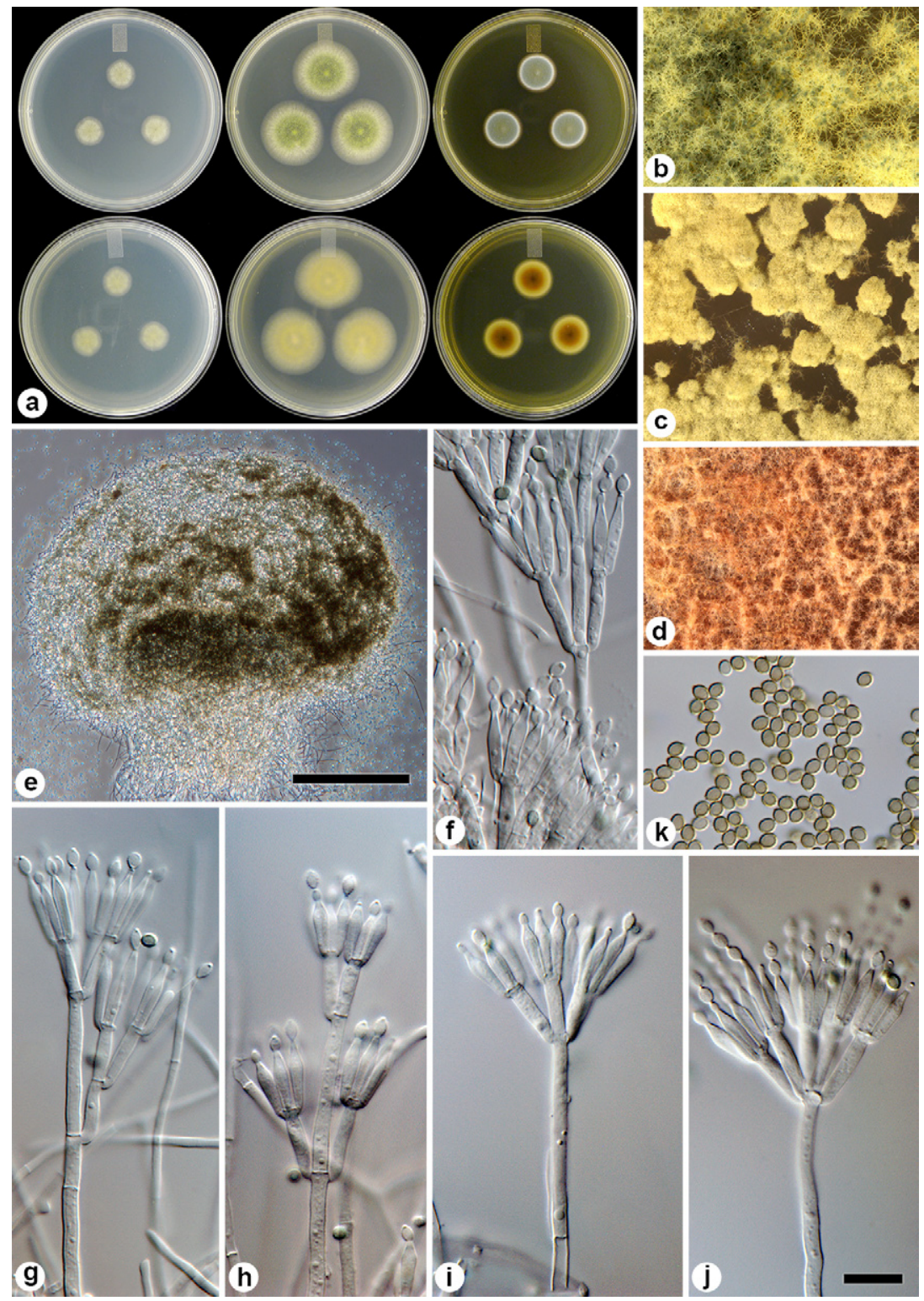

PlATe 2. Talaromyces flavovirens as it occurs in culture. a. Colonies grown for 7 days at $25^{\circ} \mathrm{C}$ on CYA, MEA and YES from left to right (top row = obverse, bottom row = reverse). b. Colony texture on MEA after 7 days. c. Colony texture on MEA after prolonged incubation showing synnemata produced being covered by the sterile yellow capitulum. d. Colonies on CYA after prolonged incubation, becoming brick red. e. Synnemata produced on MEA after prolonged incubation. $\mathbf{f}-\mathbf{j}$. Typical conidiophores. k. Ellipsoidal heavy walled conidia. Scale bars: $\mathrm{e}=50 \mu \mathrm{m} ; \mathrm{j}$ (applies to $\mathrm{f}-\mathrm{k}$ ) $=10 \mu \mathrm{m}$. 
mass Greyish Turquoise (24E4-24E6); exudate absent, soluble pigment absent; margins narrow ( $3 \mathrm{~mm}$ ), low, entire; reverse Dark Brown (6F8) at colony centre, fading to Light Brown (6D8) nearing the Greyish Green (30D5) margin, in some strains brown shades lacking, then similarly colored to MEA. On CYA at $5^{\circ} \mathrm{C}$ after 7 DAYs - no growth. On CYA at $37^{\circ} \mathrm{C}$ after 7 DAYs - no growth.

Synnemata as described above for the natural substrate. Conidiophores closely packed together, mostly biverticillate although terverticillate branching is not uncommon, smooth walled, $95-325 \times 2-3 \mu \mathrm{m} ; 2-3$ basal branches sometimes present, branches varying greatly in length, $10-35 \times 2-3 \mu \mathrm{m}$; metulae 4-6 per stipe or branch, cylindrical, forming angles of $25-70^{\circ}, 9-15$ $\times 2-3 \mu \mathrm{m}$. Phialides acerose, in nature with a greenish pigment, in culture pigmentation less obvious, $5-8$ per metula, $8-10.5(-11.5) \times 2-3 \mu \mathrm{m}$. Conidia prolate, rough-walled, connective scars often visible, $2.5-3.5 \times 2-2.5$ (mean \pm stdev $=2.98 \pm 0.16 \times 2.3 \pm 0.13) \mu \mathrm{m}$, mean width/length $=0.75 \pm 0.05, \mathrm{n}=71$, with 'giant' conidia sometimes present, up to $4.5-5.5 \times 3.5-4 \mu \mathrm{m}$.

HaвiтAт: Leaves of Quercus suber, Q. ilex, and Cistus salviifolius.

Distribution: Spain, Algeria.

Additional specimens examined: SPAIN, Catalonia, Port de la Selva, Girona, Font Clareta, on leaves of Quercus suber, 3.I.2006, X. Llimona (DAOM 236381, BCN 14.000); Selva de Mar, Girona, 3.I.2006, X. Llimona (DAOM 236382, BCN 14.003); same location, 31.XII.2006, X. Llimona (DAOM 242312); Barraca d'en Rabert, Pau, Girona, 31.XII.2005, X. Llimona (DAOM 236383, BCN 14.006); VAlencia, Xóvar, Alt Palàcia, on leaves of Q. suber, 29.XI.2005, X. Llimona, J. Vila, F. Teiedor (DAOM 236384, BCN 14.009). Extremadura, Finca Las Cansinas, Monfragüe, Cácera, on leaves of Q. suber, 14.XI.1986, R. Galáno no. 507 (DAOM 242311).

\section{Discussion}

Talaromyces flavovirens is distinguished from other synnematous Talaromyces species (T. calidicanius, T. chloroloma, T. cecidicola, T. coalescens, T. dendriticus, T. palmae, T. panamensis, T. pseudostromaticus, and T. ramulosus) by the characteristic yellow, short stalked, mycetozoa-like synnemata produced both in nature and in culture. The yellow color is caused by an almost peridium-like hyphal covering of the conidial head, which is much denser than the aerial mycelium that sometimes covers conidiophores of other Talaromyces species. Ascomata have so far only been observed in nature, with ascocarps eventually producing thick walled, spiny ascospores. The ecology of T. flavovirens, as described by Llimona et al. (2006), is rather specific. The species occurs on dead leaves of Quercus suber, rarely Q. ilex, and Cistus salviifolius, which have not fallen from trees by normal senescence, but rather by physical events such as wildfires, hail or breaking of branches. These leaves are thus killed with their full complement of nutrients, apparently favouring the growth of this fungus. The currently known distribution suggests that this is a moderately thermotolerant, Mediterranean species. 
The 1824 specimen from Madrid collected by M.C. Durieu de Maisonneuve (PC 0088796) on leaves of Quercus ilex probably represents the Spanish material mentioned by Durieu (1848) and is designated as lectotype of L. flavovirens above. The Algerian specimens from la Calle reported by Durieu (1848) were also examined (PC088798, PC0088795), but lack ascomata. It is possible to infer that Montagne (1845) based the description in the protologue on both Algerian and Spanish material, because in the Flore d'Algérie (1848, p. 398), an 1824 collection by Durieu from Madrid is mentioned. Observations of the lectotype by XL demonstrated the occurrence of both ascospores and conidia on this specimen, making it a suitable lectotype for this pleiomorphic species. The alternative, lectotypification using the 1846 illustration, would be less desirable given the lack of conclusive evidence of ascomata. We designated the holotype of $P$. aureocephalum as the epitype of T. flavovirens to stabilize the synonymy of these two names.

We were unable to prove unequivocally the genetic connection between the putative asexual and sexual states of $T$. flavovirens but feel that the evidence is convincing. Ascomata were never observed in our single spore derived strains or crossed cultures, although structures that could be interpreted as unfertilized ascomata were sometimes produced. Amplification and sequencing of the mating type genes confirmed that $T$. flavovirens is heterothallic, with individual isolates containing either the MAT1 or MAT2 genes, never both. A recent paper reported the development of a sexual stage for T. pinophilus (López-Villavicencio et al. 2010), a close relative of T. flavovirens, induced only after media dried out. The similarity with the arid habitat of T. flavovirens is interesting, but in our experiments slow drying of the colonies did not induce maturation of the putative ascoma initials.

Comparatively large, prolate ascospores with thick spiny walls were observed, a character also typical for T. flavus and T. macrosporus. Ascospore sizes were thought to be useful for distinguishing T. flavus $(3-5 \times 2.2-3.5 \mu \mathrm{m})$ and T. macrosporus $(5-6.5 \times 3.5-5.2 \mu \mathrm{m})$ (Stolk \& Samson 1972), but T. flavovirens with its broader size range $(4-7 \times 3-4 \mu \mathrm{m})$ complicates this distinction. Based on ascospores alone, T. flavovirens is difficult to distinguish from $T$. flavus and T. macrosporus, but the distinctiveness of its synnematous morph makes identification simple.

Based on morphological similarities between the sexual states of T. flavovirens, T. macrosporus, and T. flavus, they were expected to be close relatives in the phylogenetic analyses. Talaromyces flavovirens is resolved in clade 1 of Samson et al. (2011), which has little variation in the ITS barcodes. This results in a weak phylogenetic signal, confirming only that T. flavovirens itself forms a coherent clade with bootstrap support. The $\beta$-tubulin gene has more sequence variation than the ITS and thus provides better species resolution. In the 
$\beta$-tubulin phylogeny, T. flavovirens was resolved as a close relative of T. apiculatus ${ }^{a}$, T. galapagensis, T. siamensis ${ }^{a}$, and two small clades containing Penicillium liani, Talaromyces funiculosus ${ }^{a}$, T. macrosporus, and T. pinophilus ${ }^{a}$. Amongst these close relatives, are species that lack a known sexual state, marked with ${ }^{a}$. Based on asexual structures, these species are easily distinguished from $T$. flavovirens. Concerning the sexually competent species in this clade, T. flavus and T. macrosporus are discussed in the previous paragraph. Otherwise, T. galapagensis has the most similar ascomata but it produces ascoma initials that are thin hyphae (Samson \& Mahoney 1977). Its ascospores, although similarly ornamented, are much bigger $(7-10 \times 5.5-8 \mu \mathrm{m})$ than those of T. flavovirens. Other species that produce synnemata are resolved as distant relatives to T. flavovirens. Interestingly though, a clade of synnemata producers occurs in the $\beta$-tubulin analysis (FIG. 1). This clade occurs in analyses of other genes as well, and some kind of fungus-insect relationship was hypothesized for some of these species (Seifert et al. 2004, Visagie et al. 2009). This idea is being investigated more carefully in our continuing studies of these species.

\section{Acknowledgements}

This study was part of an overseas visit by the first author, made possible by funding from the South African Biosystematics Initiative, NRF. The fieldwork by X. Llimona in Catalonia was funded by the Institut d'Estudia Catalans (PT2008-S0206). We are grateful to the curators of PC and DAOM for allowing us to examine specimens in their care, JC Frisvad for providing us with the ex-type culture of $P$. aureocephalum, RA Samson and JAMP Houbraken for providing ex-type $\beta$-tubulin sequences, and $\mathrm{K}$ Jacobs for her support of the senior author's participation in this project. The authors are grateful for reviews by SW Peterson and RA Samson.

\section{Literature cited}

Durieu de Maisonneuve MC. 1846. Lasioderma flavo-virens DR. et Montg. Exploration scientifique de l'Algérie, Botanique 1(4): t.20 f.4.

Durieu de Maisonneuve MC. 1848. Exploration scientifique de l’Algérie, Botanique 1(10): 361-400.

Gascuel O, 1997 BIONJ: An improved version of the NJ algorithm based on a simple model of sequence data. Molecular Biology and Evolution 14: 685-695.

http://dx.doi.org/10.1093/oxfordjournals.molbev.a025808

Glass NL, Donaldson GC. 1995. Development of primer sets designed for use with the PCR to amplify conserved genes from filamentous Ascomycetes. Applied and Environmental Microbiology 61:1323-1330.

Hadley A. 2006. CombineZ, version 5. Published by the author. www.hadleyweb.pwp

Höhnel F von. 1910. Fragmente zur Mykologie (X. Mitteilung, Nr. 468 bis 526). Sitzungsberichte der Kaiserlichen Akademie der Wissenschaften Math.-naturw. Klasse Abt. I. 119: 393-394.

Houbraken J, Samson RA. 2011. Phylogeny of Penicillium and the segregation of Trichocomaceae into three families. Studies in Mycology 70: 1-51.

Katoh K, Asimenos G, Toh H. 2009. Multiple alignment of DNA sequences with MAFFT. Methods Mol Biol 537: 39-64. http://dx.doi.org/10.1007/978-1-59745-251-9_3 
Kornerup A, Wanscher JH. 1966. Methuen handbook of color. Denmark, Sankt Jørgen Tryk.

Lindau G. 1900. Hyphomycetes. In: A Engler, K Prantl (eds). Die natürlichen Pflanzenfamilien $1\left(1^{\star *}\right):$ 415-517, 558-559.

Llimona X, Vila J, Garcia-Porta TM, Tejedor F. 2006. Penicillium aureocephalum Munt.-Cvetk., Hoyo et Gómez-Bolea, un interessant Ascomicet anamòrfic amb aspecte de mixomicet. Distribució, ecologia i fenologia. Revista Catalana de Micologia 28: 47-56.

López-Villavicencio M, Aguileta G, Giraud T, Vienne DMD, Lacoste S, Couloux A, Dupont J, 2010 Sex in Penicillium: Combined phylogenetic and experimental approaches. Fungal Genetics and Biology 47: 693-706. http://dx.doi.org/10.1016/i.fgb.2010.05.002

Montagne JPFC. 1845. Cinquième Centurie de plantes cellulaires exotiques nouvelles. Décades VII à X. Annales des Sciences Naturelles, Botanique, 3e Sér., 4: 346-367.

Muntañola-Cvetković M, Hoyo P, Gómez-Bolea A. 2001. Penicillium aureocephalum anam. sp. nov. Fungal Diversity 7: 71-79.

Okuda T, Klich MA, Seifert KA, Ando K. 2000. Media and incubation effects on morphological characteristics of Penicillium and Aspergillus. 83-99, in: RA Samson, JI Pitt (eds). Integration of modern taxonomic methods for Penicillium and Aspergillus classification. Amsterdam, Harwood academic publishers.

Oudemans CAJA. 1920. Enumeratio systematica fungorum in omnium herbarum Europaearum organis diversis hucusque observatorum mentione facta fontium litterariorum diagnoses eorum figurasque proferentium. Vol. 2. Nijhof, The Hague.

Pitt JI. 1979. The genus Penicillium and its teleomorphic states Eupenicillium and Talaromyces. London, Academic Press Inc.

Saccardo PA. 1886. Sylloge Hyphomycetum. Sylloge Fungorum 4. 807 p.

Samson RA, Mahoney P. 1977. Talaromyces galapagensis sp.nov. Transactions of the British Mycological Society 69: 158-160.

Samson RA, Yilmaz N, Houbraken J, Spierenburg H, Seifert KA, Peterson SW, Varga J, Frisvad JC. 2011. Phylogeny and nomenclature of the genus Talaromyces and taxa accommodated in Penicillium subgenus Biverticillium. Studies in Mycology 70: 159-183. http://dx.doi.org/10.3114/sim.2011.70.04

Schoch CL, Seifert KA, Huhndorf S, Robert V, Spouge JL, Levesque CA, Chen W, Fungal Barcoding Consortium. 2012. Nuclear ribosomal internal transcribed spacer (ITS) region as a universal DNA barcode marker for Fungi. PNAS 109: 6241-6246.

http://dx.doi.org/10.1073/pnas.1117018109

Seifert KA, Hoekstra ES, Frisvad JC, Louis-Seize G. 2004. Penicillium cecidicola, a new species on cynipid insect galls on Quercus pacifica in the western United States. Studies in Mycology 50: 517-523.

Seifert KA, Frisvad JC, Houbraken J, Llimona X, Peterson SW, Samson RA, Visagie CM. 2012. (2051) Proposal to conserve the name Talaromyces over Lasioderma (Ascomycota). Taxon 61(2): 461-462.

Stolk AC, Samson RA. 1972. The genus Talaromyces: studies on Talaromyces and related genera II. Studies in Mycology 2: 1-65.

Swofford, D. L. 2002. PAUP*. Phylogenetic Analysis Using Parsimony (*and Other Methods). Version 4. Sinauer Associates, Sunderland, Massachusetts.

Visagie CM, Roets F, Jacobs K. 2009. A new species of Penicillium, P. ramulosum sp. nov., from the natural environment. Mycologia 101: 888-895. http://dx.doi.org/10.3852/08-149

White TJ, Bruns T, Lee S, Taylor J. 1990. Amplification and direct sequencing of fungal ribosomal RNA genes for phylogenetics. 315-322, in: MA Innis et al. (eds). PCR Protocols: a guide to methods and applications. San Diego, Academic Press. 